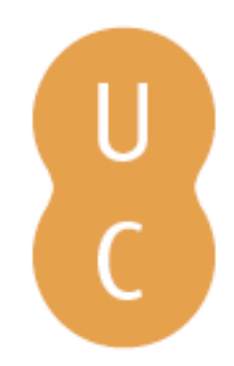

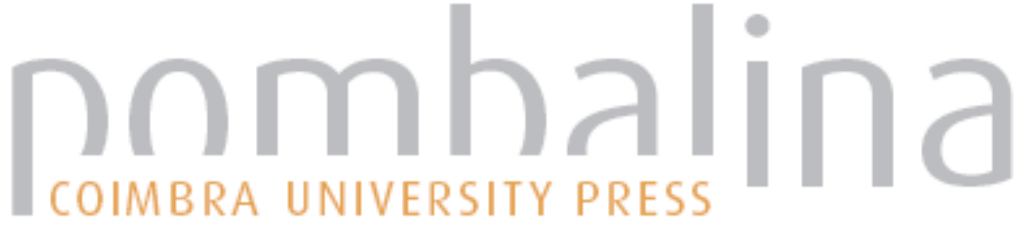

\section{A Rússia e a Ásia Central: globalização e competição hegemónica}

Autor(es): $\quad$ Simão, Licínia

Publicado por: Imprensa da Universidade de Coimbra

URL

persistente: URI:http://hdl.handle.net/10316.2/31906

DOI: $\quad$ DOI:http://dx.doi.org/10.14195/978-989-26-0712-2_4

Accessed : $\quad$ 26-Apr-2023 07:51:09

A navegação consulta e descarregamento dos títulos inseridos nas Bibliotecas Digitais UC Digitalis, UC Pombalina e UC Impactum, pressupõem a aceitação plena e sem reservas dos Termos e Condições de Uso destas Bibliotecas Digitais, disponíveis em https://digitalis.uc.pt/pt-pt/termos.

Conforme exposto nos referidos Termos e Condições de Uso, o descarregamento de títulos de acesso restrito requer uma licença válida de autorização devendo o utilizador aceder ao(s) documento(s) a partir de um endereço de IP da instituição detentora da supramencionada licença.

Ao utilizador é apenas permitido o descarregamento para uso pessoal, pelo que o emprego do(s) título(s) descarregado(s) para outro fim, designadamente comercial, carece de autorização do respetivo autor ou editor da obra.

Na medida em que todas as obras da UC Digitalis se encontram protegidas pelo Código do Direito de Autor e Direitos Conexos e demais legislação aplicável, toda a cópia, parcial ou total, deste documento, nos casos em que é legalmente admitida, deverá conter ou fazer-se acompanhar por este aviso.

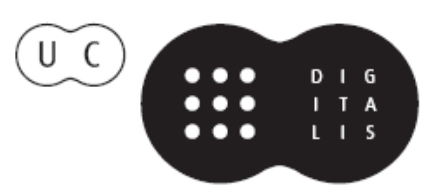


IMPRENSA DA

UNIVERSIDADE

DE COIMBRA

COIMBRA

UNIVERSITY

PRESS

\section{A POLÍTICA EXTERNA \\ RUSSA NO ESPAÇO \\ EURO-ATLÂNTICO}

$\therefore:$

\section{Dinâmicas de cooperaçấo e}

competiçẫo num espaço alargado

PÁTRICIA DAEHNHARDT

MARIA RAQUEL FREIRE

Coordenadoras 
(Página deixada propositadamente em branco) 
CAPÍTULO 4

\section{A RúSSIA E A ÁSIA CENTRAL: GLOBALIZAÇÃO E COM P E T I Ç Ã O H E G E M Ó I C A}

Licínia Simão

\section{Introdução}

A presença da Federação Russa no espaço da Ásia Central, incluindo as cinco ex-repúblicas Soviéticas (Cazaquistão, Quirguistão, Tajiquistão, Turquemenistão e Uzbequistão) tem vindo a reforçar-se de forma gradual desde o fim da União Soviética (União das Repúblicas Socialistas Soviéticas, URSS). À medida que a política externa russa abandonou o ocidente como prioridade central, após o período de entusiasmo inicial, e se concentrou na afirmação de uma esfera de influência no seu 'estrangeiro próximo' (na Comunidade de Estados Independentes (CEI)), visível já, em meados da década de 1990, as relações com a Ásia Central voltaram a ser uma parte fundamental dos interesses russos. A reentrada da Rússia neste espaço geográfico coincidiu, contudo, com a abertura da Ásia Central às dinâmicas da globalização económica e geopolítica, dividindo a região entre polos distintos de atração: o ocidente, a Rússia e a China. Na área económica, a atuação das organizações internacionais de desenvolvimento como as Nações Unidas e o Banco Mundial, a par dos investimentos dos Estados Unidos da América (EUA) e das potências europeias no sector energético, foram fatores fundamentais de sustentabilidade financeira, enquanto a entrada da China nos mercados centra-asiáticos abriu importantes novas possibilidades de desenvolvimento socioeconómico. A nível 
político e de segurança, as oportunidades de cooperação com a potência global, os Estados Unidos, com a Organização do Tratado do Atlântico Norte (OTAN) e a Organização para a Segurança e Cooperação na Europa (OSCE), reforçaram a presença ocidental e deram um sinal importante de envolvimento na região. Este contexto conduziu, contudo, também ao desenvolvimento de dinâmicas competitivas entre os interesses ocidentais e a Rússia e a China, principalmente no âmbito da cooperação regional de segurança, materializadas na Organização de Cooperação de Xangai (OCX).

A política externa russa teve, pois, de lidar com esta realidade complexa à medida que definia as suas prioridades nesta região. Efetivamente, o processo de reafirmação dos interesses russos evidenciou, numa fase inicial, uma natureza reativa aos acontecimentos no terreno (por exemplo, à guerra civil no Tajiquistão ou à presença crescente das companhias energéticas ocidentais no Cáspio). Com a chegada do presidente Putin ao Kremlin, em 2000, os interesses russos na região tornam-se mais claros e a estratégia de atuação tornou-se mais determinada, em resposta a estas novas dinâmicas. O recurso à institucionalização da cooperação económica e de segurança foi uma forma, relativamente barata, de manter a região sob influência de Moscovo, por exemplo através da criação da Comunidade Económica da Eurásia (CEdE) ou do Tratado de Segurança Coletiva (TSC) ${ }^{32}$, em 1992, ao passo que o investimento nos recursos energéticos se adequou à estratégia russa de se transformar na principal potência energética da Eurásia. Num momento em que o acesso aos recursos energéticos é uma questão central para o crescimento económico internacional, o monopólio russo sobre o acesso às reservas energéticas da Ásia Central, que se manteve até 2009, foi uma peça importante na afirmação internacional russa (Kramer, 2009).

Por fim, a mais recente dinâmica a afetar os processos de globalização e competição hegemónica na Ásia Central foi a guerra global contra o terrorismo. Após os acontecimentos de 11 de setembro de 2001 nos EUA

32 O TSC é uma aliança de defesa mútua, que estabelece mecanismos de consulta e assistência militar, no caso de ataque externo a um dos seus membros (Arménia, Bielorrússia, Cazaquistão, Quirguistão, Federação Russa, Uzbequistão e Tajiquistão). Em maio de 2002, foi estabelecida a Organização do Tratado de Segurança Coletiva. 
e a consequente guerra no Afeganistão, os regimes da Ásia Central passaram a estar no centro da atenção internacional. Não só a potência global, os EUA, se apresentou sensível ao problema do terrorismo, que era desde a independência um problema grave para as sociedades da Ásia Central (incluindo o Afeganistão), como se apresentou disponível para atuar militarmente. Para a Federação Russa, este foi, porventura, o maior desafio aos seus interesses, já que, até esta altura, a Rússia mantinha o monopólio da presença militar externa na Ásia Central. Face aos processos de crescente interdependência global e à sua sobreposição às dinâmicas de competição hegemónica nesta região, a segurança da Ásia Central tornou-se objeto de disputa, mais do que de reflexão cuidada e de cooperação. Para a Federação Russa, estes foram desafios importantes para a sua política externa pós-Guerra Fria, não só por a Ásia Central ser um dos últimos redutos de influência no espaço da ex-URSS, mas também pelas dinâmicas de interdependência que regulam o atual sistema internacional e que ligam os interesses de Moscovo, com os de Pequim e de Washington.

\section{Competição hegemónica}

Alguns autores sugerem que a Rússia está destinada a permanecer um ator fundamental na Ásia Central, mesmo que não represente o destino final desta região (Garnett, Rahr e Watanabe, 2000, p. 71). A abertura da Eurásia aos processos de interdependência e competição globais representa um leque vasto de novas possibilidades para estes Estados, usado para manter a Rússia a uma distância de segurança, no que concerne a afirmação pós-independência das nacionalidades da Ásia Central e a persecução dos interesses das elites nacionais.

Entre estas possibilidades está a cooperação com os EUA e a OTAN. Logo, isto significa que qualquer processo de reafirmação hegemónica da Rússia nesta região está destinado a entrar em conflito direto com a presença e os interesses da potência hegemónica global, ou seja, os EUA. Podemos pois falar de uma hegemonia multinível na Ásia Central (Deyermond, 2009), onde se incluem a potência hegemónica global (os EUA), uma 
potência hegemónica regional em reafirmação (a Rússia), uma potência aspirante a nível sub-regional (o Uzbequistão) (Deyermond, 2009, pp. 162-164; Buzan e Waever, 2003, p. 425), bem como potências hegemónicas externas aspirantes, como a China e a Índia (Laruelle, Peyrouse, Huchet e Balci, 2010). Este cenário complexo torna os cálculos de todos os atores envolvidos muito incertos, aumentando a possibilidade de competição estratégica, em detrimento de abordagens mais cooperativas, face aos desafios que se colocam à segurança regional, tal como analisado mais à frente, neste capítulo.

O modelo da hegemonia multinível é particularmente útil para tratar as relações de poder de natureza muito complexa na região da Ásia Central, uma vez que fornece um quadro analítico para abordar, de forma relacional, os interesses dos diferentes atores presentes nesta região e como estes são constrangidos ou potenciados nas suas relações com outras potências hegemónicas neste contexto regional. Quando há coincidência de interesses entre potências hegemónicas, Deyermond (2009, p. 151) apelida esta situação de um "modelo hegemónico matrioska [onde] as potências hegemónicas nos diferentes níveis podem acomodar-se mutuamente, de forma pacífica e formar alianças, quando os seus interesses coincidirem". Esta é uma visão informada pela escola realista das Relações Internacionais, onde a cooperação é possível e desejável apenas quando isso reforçar os interesses dos atores envolvidos. A cooperação não é, pois, um objetivo em si, senão uma necessidade de curto prazo e que pode ser revogada quando o cálculo de interesses for alterado. Perante esta lógica, partilhada pela maioria dos atores estatais nesta região, a possibilidade de desenvolver e enraizar uma visão cooperativa, como resposta aos desafios regionais, parece também não ser suportada pelos parceiros externos da região.

O modelo da hegemonia multinível é também relevante para avaliar o potencial de conflito em regiões onde a competição hegemónica se desenvolve, como é o caso da Ásia Central. Este modelo concebe a hegemonia como "um conceito multifacetado, em que a hegemonia num dos níveis representa um desafio à hegemonia noutro nível, mas não a faz desaparecer" (Deyermond, 2009, p. 157). Além disso, perante a possibili- 
dade de coexistência hegemónica multinível, o potencial de conflito entre as diferentes potências hegemónicas deve ser avaliado tendo por base a natureza complexa das suas relações, onde a competição e a cooperação são possíveis em diferentes níveis. Quais são, então, as possibilidades de acomodação e cooperação ao nível sub-regional, na Ásia Central? De que forma tem a potência regional gerido o desafio colocado pela potência hegemónica global e as potências hegemónicas externas aspirantes? Poderão existir compensações de outras áreas de interação entre potências hegemónicas, com impacto no contexto regional da Ásia Central?

A interação entre a Federação Russa e os EUA tem sido, porventura, um dos factores de maior destabilização regional na Ásia Central, desde o fim da Guerra Fria. Se analisarmos a forma como ambos têm gerido as suas ambições na região, podemos verificar que a presença norte-americana tem-se pautado por uma lógica imediatista, conduzida por interesses voláteis, definidos conforme a Administração na Casa Branca e sem um plano de longo prazo de estabilização e desenvolvimento da região. Por isso, são visíveis momentos e áreas de interesse, como foi a década de 1990 e o investimento no acesso às reservas energéticas do Cáspio, sob pressão das grandes companhias energéticas norte-americanas. Depois dos acontecimentos de 11 de setembro de 2001, e face à guerra global contra o terrorismo e às operações militares no Afeganistão, a importância estratégica da Ásia Central para a potência hegemónica global aumentou exponencialmente. Hoje, a estabilização do Afeganistão e dos seus vizinhos é uma prioridade da Administração Obama, no âmbito da anunciada retirada militar do cenário afegão, em 2014. Esta política norte-americana de interesses pragmáticos de curto prazo tem sido vista pela Rússia como um desafio direto aos seus interesses e à sua posição no contexto da Ásia Central, principalmente por oferecer aos líderes regionais uma alternativa às relações com Moscovo, o que tem consolidado a competição como a principal característica nas relações regionais. No entanto, por ser um envolvimento pragmático, ditado por interesses concretos ligados principalmente ao conflito afegão, Moscovo sabe que esta presença norte-americana pode ser revista quando outros interesses mais relevantes surgirem. 
Esta situação apresenta dois problemas para a estabilização regional. Primeiro, a falta de um compromisso alargado e de longo prazo com a estabilidade e a segurança na Ásia Central, nomeadamente interligando a guerra contra as forças talibãs no Afeganistão ao combate ao tráfico de droga e à cooperação para o desenvolvimento na Ásia Central. As políticas de interesses imediatos norte-americanas têm conduzido a compromissos hesitantes com as reformas democráticas e de direitos humanos, numa região onde o autoritarismo é frequentemente recompensado. Estas são áreas que a potência hegemónica global poderia fazer valer na região, face a outras potências como a Rússia ou a China, mas que Washington vê como enfraquecendo a sua posição, ao invés de a fortalecer. Este é um entendimento que tem em linha de conta a posição das elites da Ásia Central, para quem a permanência no poder é o objetivo máximo, em detrimento de uma visão mais solidária com os povos da região, para quem as potências ocidentais representam (ainda que com crescente relutância) um imaginário de igualdade e prosperidade. Nesse sentido, a dimensão normativa da política externa dos EUA é simultaneamente um problema nas suas relações com os regimes ditatoriais da região e insuficiente para exigir reformas e mudanças estruturais.

O segundo problema resulta da sobreposição entre os esforços dos EUA e da Rússia para se (re)afirmarem como potências no contexto euroasiático, no pós-Guerra Fria, e da crescente complexidade das relações entre os dois atores ao nível global. Na década de 1990, e perante o aumento da presença norte-americana no Cáspio, a Rússia procurou reforçar a sua presença comercial na região, fazendo uso dos laços privilegiados herdados da URSS. Já sob liderança do presidente Putin, o Kremlin iniciou também um processo de reafirmação regional, incluindo uma gradual revisão das estruturas de cooperação lideradas pela Rússia e fazendo uso do seu significativo orçamento, como resposta aos desafios da guerra global contra o terrorismo e à presença militar dos EUA na Ásia Central. Finalmente, e desde os acontecimentos de Andijon, no Uzbequistão, em $2005^{33}$, a influência russa consolidou-se junto dos líderes regionais, fruto

33 A 13 de maio de 2005, um protesto juntou cerca de 10000 pessoas na cidade uzbeque de Andijon, no Vale de Fergana, em resposta ao julgamento de 23 empresários locais, 
do apoio político de Moscovo ao princípio de não ingerência nas questões internas dos Estados. Esta opção revelou-se particularmente proveitosa, tendo em conta a reação europeia e norte-americana de impor sanções ao regime de Tasquente, incluindo o fim do uso da base aérea uzbeque, de Khanabad, pelas tropas aliadas, na guerra do Afeganistão, a partir de novembro de 2005.

Esta é, pois, uma situação em que os EUA e a Rússia têm competido diretamente, embora tenham também entrado em cooperação, nomeadamente após o 'reset' de relações entre Washington e Moscovo, com as administrações Obama e Medvedev. A política de 'reset' de relações com Moscovo foi uma das primeiras iniciativas de política externa da administração Obama, com o objetivo de "reverter a "perigosa deriva" 34 em curso nas relações bilaterais entre os EUA e a Federação Russa, manifesta principalmente durante o segundo mandato do presidente George W. Bush. No âmbito desta política, as questões de armamento nuclear, cooperação com a OTAN e os esforços de guerra no Afeganistão têm sido áreas onde os dois atores têm conseguido encontrar terreno mútuo de entendimento, principalmente face aos fracos resultados da cooperação dos EUA com a potência regional em aspiração, o Uzbequistão. Em linha com o quadro de análise da hegemonia multinível, isto abre possibilidades simultâneas de cooperação, nomeadamente na estabilização do Afeganistão, e dinâmicas de competição, relativamente à presença militar e aos recursos energéticos.

A política de 'reset' não tem sido suficiente para alterar esta situação, apesar das numerosas oportunidades de cooperação com vista a uma estabilização regional e global e, hoje, encontra-se virtualmente extinta com o regresso ao Kremlin do Presidente Putin e o contexto crispado das relações EUA-Rússia face aos conflitos no Médio Oriente, em especial

acusados pelo regime de Islam Karimov de serem extremistas islâmicos ligados à organização pan-islâmica Hizb ut-Tahrir. As tropas uzbeques enviadas para o local abriram fogo, matando centenas de pessoas (os números exatos são desconhecidos).

${ }^{34}$ Informação disponível na página oficial da Casa Branca, "U.S.-Russia Relations: 'Reset' Fact Sheet", The White House, Office of the Press Secretary, 24 de junho de 2010. http:// www.whitehouse.gov/the-press-office/us-russia-relations-reset-fact-sheet. Consultado em: 14 fevereiro 2012. 
a guerra na Síria. A guerra no Afeganistão foi, naturalmente, a principal oportunidade para desenvolver esta cooperação entre os dois atores. A Rússia afirmou o seu compromisso em dar assistência aos esforços de guerra das potências ocidentais e partilha com elas um interesse genuíno em travar o islamismo radical no seu estrangeiro próximo e em limitar o impacto pernicioso que o tráfico ilícito de drogas tem na sua própria sociedade. No entanto, a Rússia vê a guerra no Afeganistão como um trunfo nas suas relações com os EUA e a OTAN (Stepanova, 2009, p. 2), aumentando a relevância estratégica de Moscovo. Perante esta instrumentalização do contexto regional de segurança nos cálculos estratégicos de poder e influência de ambos os atores, existe o risco de, nem os EUA definirem uma estratégia coerente de luta contra o tráfico de drogas e as atividades transnacionais terroristas na Ásia Central, nem a Rússia reconhecer a importância fundamental de estabilizar o Afeganistão, com vista ao controlo do tráfico de droga e dos movimentos islâmicos de cariz radical. A forma como Washington e Moscovo gerirem entre si a estabilização da Ásia Central, no contexto pós-guerra do Afeganistão, será crucial. Neste sentido, a intenção norte-americana de criar uma base militar permanente em território afegão e os receios russos de que a gestão da segurança regional seja deixada exclusivamente ao seu cuidado podem significar que, no futuro, algum nível de cooperação será possível, apesar da retórica inflamada entre as partes. Uma posição clara em Moscovo passa por aceitar envolver-se na reconstrução do Afeganistão, mas está fora de questão um envolvimento militar.

Os processos eleitorais na Rússia (eleições presidenciais em março de 2012) e nos EUA (eleições presidenciais em novembro de 2012) traduziram-se numa maior atenção às questões internas em detrimento de grandes decisões de política externa. Da nova Rússia de Putin, emergem sinais de maior contestação ao presidente e de maior fragmentação do Kremlin (Freire, 2012, p. 71) que poderão criar novas tensões nas relações com o ocidente e os EUA. Em Washington, a polarização do espectro político tem tido consequências preocupantes no que toca às relações com a Rússia. Se por um lado, o primeiro mandato de Obama procurou reconciliar “a visão grandiosa do presidente com o seu realismo inato e cuidado 
político" (Indyk, Kenneth e O'Hanlonthe, 2012), que no caso das relações com a Rússia e da interação entre os dois na Ásia Central se traduziu em ganhos de estabilidade imediata e apoio à estratégia norte-americana de retirada do Afeganistão, por outro lado, a visão de política externa apresentada pelo partido republicano durante a campanha presidencial norte-americana foi criticada como sendo "um regresso a uma ideologia neoconservadora intimidatória" (Jentleson e Kupchan, 2012). No caso concreto das relações com a Rússia, o candidato republicano prometia reverter o processo de aproximação a Moscovo, caracterizando o regime no Kremlin como corrupto e autoritário e a Rússia como o principal inimigo dos EUA. Uma caracterização que a imprensa russa denunciou ativamente (Friedman, 2012). A reeleição de Obama em novembro de 2012 confirmou que as relações dos EUA com Moscovo são centrais para resolver a guerra no Afeganistão e para a estabilização da Ásia Central.

\section{O complexo contexto de segurança da Ásia Central}

O estabelecimento e consolidação de Estados-nação soberanos na Ásia Central foram processos essencialmente pacíficos ao longo do período pós-Guerra Fria. Uma das áreas de tensão atual e de potencial conflito é a natureza arbitrária das fronteiras da região e a sua falta de delimitação. As fronteiras da Ásia Central foram desenhadas por Estaline, visando garantir que os principais grupos étnicos da União Soviética estivessem politicamente representados ao nível das repúblicas. Neste processo, largas minorias ficaram deslocadas, fora das fronteiras das novas repúblicas soviéticas, o que impediu a consolidação de identidades étnicas que pudessem vir a pôr em causa o poder central de Moscovo. Embora as fronteiras fossem aspetos meramente simbólicos dentro da União Soviética, depois de 1991 tornaram-se objeto de disputa. Um dos passos mais importantes para resolver a questão das fronteiras na região foi a decisão chinesa de procurar um acordo com o Cazaquistão, o Quirguistão e o Tajiquistão sobre a delimitação e desmilitarização da fronteira comum, de cerca de 3000 quilómetros (Xing, 2001, p. 154), no âmbito do Fórum de Xangai. Por oposição, uma 
das áreas onde a delimitação de fronteiras ainda não foi possível é o Mar Cáspio, o que representa um obstáculo ao desenvolvimento dos recursos energéticos da região (Pratt e Schofield, 1997; Janusz, 2005).

O Vale de Fergana é, de longe, o assunto mais complexo, no que toca à delimitação de fronteiras na Ásia Central. Grandes secções das fronteiras entre o Uzbequistão e o Quirguistão e entre o Uzbequistão e o Tajiquistão permanecem sob disputa. Um outro factor adicional de tensão é o facto de esta ser a zona mais fértil de toda a Ásia Central, com recursos naturais como terra arável e água a serem disputados. Embora a maior parte das disputas tenha sido gerida a nível local, entre as diferentes comunidades, existe potencial para conflito inter-estatal (Swanstrom, Cornell e Tabishalieva, 2005, p. 17). As preocupações uzbeques com o terrorismo e a luta do regime contra o Movimento Islâmico do Uzbequistão (MIU), particularmente ativo no Vale de Fergana, tornaram a gestão das fronteiras e a segurança transfronteiriça num problema regional. Ilustrando esta questão, em 1999, o Uzbequistão fechou as suas fronteiras no Vale e lançou ataques aéreos sobre o sul do Quirguistão, após duas explosões em Tasquente. Os ataques aéreos, sem autorização quirguiz, provocaram a morte da uma dezena de civis e elevaram o nível de tensão entre os dois vizinhos (Internation Crisis Group, 2002b, p. 14). A presença de enclaves uzbeques no Quirguistão e a importante minoria uzbeque no norte do Tajiquistão têm sido usadas pelo regime de Islam Karimov, para exercer pressão sobre os seus vizinhos mais pequenos e mais pobres, em disputas de água e na luta contra a ameaça islâmica radical, com vista à consolidação de uma posição hegemónica sub-regional.

As disputas fronteiriças tornam-se particularmente complexas quando se sobrepõem a ameaças de segurança não tradicionais e de natureza transnacional. Redes de crime organizado transnacional têm-se infiltrado na Ásia Central, alimentando-se do lucrativo narcotráfico do Afeganistão e minando as instituições nacionais. A maior fatia do narcotráfico vindo do Afeganistão ocorre hoje ao longo da antiga Rota da Seda, pela Ásia Central (Fenopetov, 2006), em parte devido à falta de controlos fronteiriços funcionais. O narcotráfico, tal como as preocupações com a ameaça terrorista, têm materializado e endurecido as fronteiras terrestres da 
CEI (Allison, 2001, p. 258), com impacto negativo nos processos de integração económica e de desenvolvimento social. O narcotráfico afeta também a legitimidade das instituições nacionais (Lubin, 2004, p. 364), conduzindo a situações de "captura de Estados" (Cornell, 2006), especialmente no Quirguistão e no Tajiquistão. A crise política de abril de 2010 no Quirguistão, que conduziu à queda do presidente Bakiev, lançou luz sobre o nível de cooperação da elite no poder com as redes de crime organizado ativas no sul do país e ilustrou os perigos subjacentes ao cruzamento de divisões de natureza étnica, regional e social com interesses criminosos (Marat, 2008; 2010).

O narcotráfico na Ásia Central tem contribuído também para o aumento de pandemias e consumo de drogas, afetando o frágil tecido social desta região. Os níveis de pobreza mantêm-se extremamente elevados. No período imediato após o fim da URSS, entre 1990 a 1996, a diminuição do PIB das economias da Ásia Central situou-se entre os 20 e $60 \%$, tendo os efeitos desta drástica contração económica sido geridos com recurso a elevados níveis de endividamento (Hill, 2002), mas com consequências sociais devastadoras. Apesar de nos últimos anos os países da região terem apresentado crescimento económico sustentável, o impacto da crise financeira internacional de 2008 tem sido visível, parando as taxas de crescimento impressionantes do Cazaquistão e limitando de forma drástica as remessas dos emigrantes quirguizes e tajiques na Rússia (Pomfret, 2009; Gullette, 2010).

A falta de desenvolvimento económico generalizado e sustentável na Ásia Central também reflete a distribuição desigual de recursos naturais da região, onde coexistem países ricos em recursos energéticos, como o petróleo e o gás natural (o Cazaquistão, o Turquemenistão e o Uzbequistão), e países mais pobres (Quirguistão e Tajiquistão). Estes últimos controlam os recursos hídricos da região, o que lhes dá alguma margem de manobra nas suas relações com o vizinho Uzbequistão, cuja economia é altamente dependente da produção de algodão - uma cultura com uso intensivo de água (Internation Crisis Group, 2005, pp. 2-6). Além disso, a produção de energia hidroelétrica é uma das áreas de maior investimento em ambos os países, criando uma fonte de rendimento e de orgulho nacional. A 
falta de regulamentação do uso da água e da troca de água por energia faz da gestão dos recursos hídricos um tema urgente na segurança regional, com vista a evitar a escalada de tensões (Internation Crisis Group, 2002a).

Por fim, as preocupações com o terrorismo têm sido outro assunto crucial na segurança da Ásia Central, com impacto nas dinâmicas internas e externas da região. Apesar do terrorismo islâmico radical ser uma fonte muito real de preocupação para as sociedades da Ásia Central, tem sido feito um uso instrumental do Islão pelos regimes autoritários da região. É o caso no Uzbequistão, mas também no Tajiquistão e de forma mais limitada no Quirguistão (The Economist, 2010). O 11 de setembro de 2001 e o envolvimento norte-americano na região reforçaram ainda mais esta tendência de ver qualquer movimento islâmico como uma ameaça à segurança, criminalizando os movimentos religiosos ressurgentes da Ásia Central. A Rússia também considera estes movimentos islâmicos, com ligações ao Afeganistão, como uma ameaça à sua segurança, especialmente no Cáucaso do Norte. Não é, pois, surpreendente que esta tenha sido uma das áreas de maior cooperação entre Moscovo, Washington e os regimes da Ásia Central, com implicações importantes para a estabilidade regional. Contudo, o resultado desta cooperação tem sido o reforço destes regimes autoritários e repressivos, usando a bandeira do Islão radical para restringir liberdades cívicas. Tem também conduzido a uma incapacidade crónica de lidar com as ameaças à segurança, provenientes das redes terroristas transnacionais, que operam livremente na Ásia Central, com impactos muito reais na vida das populações da região.

\section{A Ásia Central na Política Externa da Federação Russa}

\section{Da independência ao 11 de setembro}

No período imediato pós-Guerra Fria, as elites russas em Moscovo demonstraram uma clara falta de visão relativamente ao futuro das relações da Rússia com o antigo império. Alguns elementos da nomenkla- 
tura defenderam que se deveria "largar o fardo pesado do ventre mole da Ásia Central" (Solzhenitsyn, citado em Rashid, 1994, p. 39; ver também Jonson, 2001, pp. 96-97). Por outro lado, a Rússia liderou a criação da CEI, com vista a gerir um 'divórcio civilizado' das Repúblicas Soviéticas e assisti-las na sua passagem para a independência (Sakwa e Webber, 1999; Markedonov, 2010). As relações da Rússia com os novos Estados independentes da Ásia Central foram simultaneamente complicadas e facilitadas pelo legado anterior. Por um lado, a política externa da Rússia independente deu prioridade às relações com o ocidente, fruto do desejo de afirmação nacionalista russa e das políticas de abertura e aproximação ao ocidente, protagonizadas por Gorbachev (Jackson, 2003, p. 55). Isto traduziu-se numa negligência inicial das relações com o antigo império, por necessidade de concentrar recursos na gestão dos problemas internos da Federação Russa e face à perceção generalizada de que qualquer tentativa de interferir nas políticas nacionais seria vista com desconfiança pelas elites da Ásia Central. As relações com a antiga potência colonial teriam de ser temperadas pelo entusiasmo nacionalista que varreu também esta região, daí que possamos dizer que a herança colonial e o contexto interno russo favoreceram um afastamento inicial.

No entanto, e face às dificuldades trazidas pela independência, alguns dos líderes da Ásia Central expressaram a sua incerteza face ao futuro da região e face ao que significaria um afastamento da Rússia. Aliás, a região da Ásia Central foi a única a votar contra o fim da União Soviética, no referendo popular de 1991. Perante esta realidade, em dezembro de 1991, a Rússia, a Bielorrússia e a Ucrânia estabeleceram a CEI e, em 1993, as cinco repúblicas centro-asiáticas aderiram à organização, reconhecendo "uma necessidade funcional de cooperação", que visava suprimir as suas necessidades militares e económicas (Sakwa e Webber, 1999, p. 381). Por isso, a colaboração com a Rússia era simultaneamente necessária, face às limitações de facto das soberanias na Ásia Central, e indesejada, tendo em conta o período pós-independência de afirmação nacionalista na região.

Em termos securitários, a guerra civil tajique, entre 1992 e 1997, representou o principal desafio à capacidade russa de influenciar a reestruturação das relações regionais. As tropas russas, que permaneciam 
na região desde o período soviético, intervieram no conflito e Moscovo envolveu-se no processo de paz, mediando uma solução para a guerra no quadro da CEI (Akiner, 2001, pp. 45-46). Outra preocupação central de segurança nas relações da Rússia, principalmente com o Uzbequistão, prendeu-se com os movimentos islâmicos radicais ativos no Vale de Fergana. Apesar dos desacordos entre Moscovo e Tasquente sobre a forma como gerir a situação no Tajiquistão, a Rússia, o Uzbequistão, o Cazaquistão e o Quirguistão concordaram em estabelecer o TSC, em 1992, em Tasquente, consolidando a cooperação de segurança e defesa no quadro da CEI (Cutler, 2006, p. 112).

Em meados da década de 1990, as políticas da Rússia para a Ásia Central alteraram-se significativamente, rumo a um envolvimento mais forte, numa altura em que o primeiro ministro Evgeny Primakov promovia o 'Eurasianismo' como o princípio central das relações da Rússia com o seu estrangeiro próximo. Isto refletia um desejo claro de recuperar o estatuto de superpotência (Jonson, 2001, p. 97), através do reforço de uma posição hegemónica na CEI e da oportunidade de consolidar uma doutrina de interesses especiais russos na ex-URSS, tal como definido já por Ieltsin e o ministro dos negócios estrangeiros Andrei Kozyrev. O Conceito de Política Externa da Federação Russa e a Doutrina Militar de 1993 confirmaram a tentativa russa de se posicionar como o principal garante político e de segurança no espaço pós-soviético (uma potência hegemónica regional), bem como o seu direito de intervir na CEI para proteger os cidadãos russos na região (Conceito de Política Externa da Federação Russa, 1993).

Durante o segundo mandato de Ieltsin, a Rússia procurou consolidar a sua presença na CEI, num equilíbrio entre o reconhecimento formal da independência dos seus vizinhos e das suas necessidades de segurança. A Rússia viu com preocupação a expansão da presença ocidental no Cáspio e na Ásia Central e procurou contrabalançá-la, uma vez que representava uma ameaça aos seus interesses e um desafio aos seus esforços de se restabelecer como uma potência hegemónica regional. Estes desafios incluíram a construção de novos oleodutos e gasodutos fora do território russo, a expansão da OTAN e o aprofundamento 
das relações entre a Aliança Atlântica e os países da CEI, através da Parceria para a Paz (PpP), bem como a cooperação militar bilateral dos EUA com a Ásia Central (Burghart, 2007, p. 8). Não é, por isso, surpreendente que a competição com os EUA tenha aumentado nos anos anteriores ao 11 de setembro, tendo culminado com a guerra na Geórgia, em 2008.35

\section{De Putin a Medvedev}

Antes das eleições presidenciais russas de março de 2000, desenvolveu-se uma nova visão da política externa e de segurança russa. O Conceito de Política Externa da Federação Russa e a Doutrina Militar de 2000 viam claramente a limitação dos interesses russos como uma ameaça central e sublinhavam a promoção de uma ordem internacional multipolar como um princípio fundamental, que deveria guiar as relações internacionais (Jonson, 2001, p. 99). Ambos os documentos refletiram um reconhecimento tácito da validade limitada que os modelos de desenvolvimento económico e político ocidentais tinham para a Rússia e abriam caminho a divergências crescentes. A crise financeira de 1998 e a crise socioeconómica que se seguiu expôs a assistência limitada que o ocidente estava disposto a estender a Moscovo e exigiu um modelo novo, mais adequado às vantagens competitivas russas. Isto significava colocar os recursos naturais no centro da atividade económica, numa altura em que os mercados internacionais começavam a beneficiar os países exportadores de petróleo e gás natural. Politicamente, a Rússia estava também longe de alcançar os padrões democráticos que os parceiros ocidentais esperavam. No Cáucaso do Norte, a gestão que Moscovo fez das guerras

35 A breve guerra de cinco dias, que opôs as forças russas e georgianas, deflagrou após a intervenção georgiana na república separatista da Ossétia do Sul, a 5 de agosto de 2008, numa tentativa de reintegrar esta região no Estado georgiano. Em apoio às autoridades separatistas, Moscovo interveio militarmente no conflito, tendo mesmo chegado a ameaçar a capital Tbilisi e o regime do presidente Saakashvili. Para um relato detalhado do contexto e acontecimentos desta guerra ver Asmus (2010). 
na Chechénia, colocou a Rússia no centro das críticas internacionais, consolidando uma clara necessidade de um modelo de desenvolvimento político alternativo para a Rússia (Kobrinskaya, 2005, p. 78).

Estas questões facilitaram a reaproximação de Moscovo aos líderes da Ásia Central. Depois de uma década de dificuldades na consolidação da independência e de grandes desilusões com as promessas do ocidente, estes líderes procuraram envolver novamente a Rússia nas questões regionais. Com o presidente Putin, Moscovo iniciou uma abordagem, preparada mais cautelosamente, de reafirmação da sua presença na Ásia Central e no Cáspio. Isto traduziu-se na institucionalização da cooperação com cada um dos Estados na sua vizinhança, bem como no uso de bens estratégicos, como as relações energéticas e as bases militares na região, para consolidar a presença russa (Laruelle, 2007). O presidente Putin demonstrou um entendimento claro das dinâmicas regionais centro-asiáticas, bem como um compromisso forte com o princípio de não ingerência nos assuntos internos dos Estados, o que foi bem recebido pelos regimes locais. Nesse sentido, uma das primeiras decisões de Putin foi dar prioridade ao Cazaquistão, assinando um acordo de cooperação com Astana, pouco tempo depois da sua eleição (Cutler, 2007, p. 117) e avançando os planos de integração económica, que levariam à entrada em funcionamento, em 2010, de uma União Aduaneira entre a Rússia, a Bielorrússia e o Cazaquistão.

Isto deu duas vantagens a Moscovo: em primeiro lugar, aproximou um parceiro difícil e que era simultaneamente um aliado importante do ocidente na extração de recursos do Cáspio; em segundo lugar, contribuiu para a competição estratégica por domínio sub-regional entre o Cazaquistão e o Uzbequistão. Um outro exemplo deste entendimento de Putin foi o apoio político de Moscovo aos frágeis regimes autoritários da região, no período pós-revoluções coloridas da Eurásia. Esta política teve o seu apogeu com o apoio claro ao presidente uzbeque, Islam Karimov, depois dos acontecimentos de Andijon, em 2005. Além disso, Moscovo manteve um compromisso inabalável com a luta contra o terrorismo no período pós-11 de setembro (Wilhelmsen e Flikke, 2005, p. 391), o que gerou empatia nos líderes da Ásia Central. 
Em geral, as políticas de Moscovo concentraram-se em dois assuntos centrais. Primeiro, em restabelecer a cooperação institucional com a Ásia Central, quer bilateralmente, quer multilateralmente em duas áreas principais: militar e económica. Com o presidente Putin, a Rússia negociou acordos militares bilaterais com o Quirguistão, em 2003 (Eurasianet, 2002), com o Tajiquistão, em 2004 (RFE/RL, 2004a), com o Uzbequistão, em 2005 (Eurasianet, 2005), e existiam já processos de cooperação militar bem estabelecidos com o Cazaquistão. A nível multilateral, em 2002, a Rússia liderou a transformação do TSC numa organização formal, a Organização do Tratado de Segurança Coletiva (OTSC), e promoveu a CEdE como uma ferramenta central no aprofundamento dos laços económicos com a região. A adesão do Uzbequistão à OTSC e à CEdE, em 2006, foi vista como uma importante vitória de Moscovo e um passo fundamental para consolidar o seu domínio hegemónico na região (Laruelle, 2007; Trenin, 2007a, p. 99). Contudo, a adesão do regime de Tasquente a estas organizações tem de ser vista no contexto da imposição de sanções pela UE e EUA, após os eventos de Andijon. A aproximação à Rússia foi, por isso, uma decisão pragmática que visava demonstrar ao ocidente que a Rússia permanece uma alternativa ao isolamento da região, mas que é, por isso mesmo, reversível. Não só o Uzbequistão não implementou nenhuma das medidas previstas pela CEdE, como saiu da organização na mesma semana em que a UE levantou as sanções ao país (Lybman e Obydenkova, 2012, p. 12) e suspendeu a sua participação na OTSC, em junho de 2012.

Em segundo lugar, a Rússia aprofundou a sua presença económica e financeira recorrendo aos recursos energéticos e minerais da região, incluindo petróleo, gás, energia hidroelétrica e minérios (Trenin, 2007b, pp. 106-110). Moscovo mostrou-se disponível para pagar preços mais elevados para aumentar o volume de energia que compra diretamente aos países da Ásia Central, de forma a garantir o controlo da maior parte da produção e exportação energética da região. Este objetivo foi reforçado pelos laços de proximidade entre o Estado e as companhias energéticas russas, como a Lukoil e a Gazprom, cujas ações podem ser interpretadas como reforçando os objetivos políticos do Kremlin (Baev, 2004, p. 272). Por fim, a Rússia investiu também na produção hidroelétrica no 
Tajiquistão e no Quirguistão, que representa a principal fonte de rendimento dos dois países. Contudo, também nesta área os ganhos russos não têm sido consolidados. Depois de aceitar diversas formas de apoio financeiro russo, as autoridades tajiques acabaram por não permitir que a Rússia participasse no desenvolvimento da barragem hidroelétrica de Rogun. Por seu lado, quer o Cazaquistão, quer o Turquemenistão desenvolveram novos oleodutos e gasodutos, ligando-os à China e ao Irão, o que efetivamente reduz o controlo russo sobre os recursos energéticos destes países (Digol, 2012, p. 192).

À medida que a Rússia procurou reverter o declínio da sua presença na Ásia Central, os acontecimentos de 11 de setembro e a guerra global contra o terrorismo representaram um desafio para Moscovo (Antonenko, 2001). Face à decisão norte-americana de intervir militarmente no Afeganistão, a Ásia Central passou a ocupar um local central na estratégia dos EUA. A resposta imediata dos líderes da Ásia Central passou por facilitar as operações dos EUA e permitir o estabelecimento de duas bases militares norte-americanas, em Manas, no Quirguistão e em Khanabad, no sul do Uzbequistão. Esta cooperação centro-asiática pode ser, em parte, explicada pela preocupação partilhada com a ameaça islâmica proveniente do Afeganistão, mas também por um cálculo estratégico. Uma cooperação mais próxima com os EUA reforçaria a política externa multivetorial destes países e manteria os apetites hegemónicos russos sob controlo. Numa tentativa de apresentar os seus interesses na Ásia Central como sendo coincidentes com os da potência hegemónica em ascensão e a potência hegemónica sub-regional, Washington teve a preocupação de, numa fase inicial, assegurar Moscovo e os regimes da Ásia Central que a sua presença na região seria de curto prazo e limitada às necessidades operacionais da guerra no Afeganistão. Contudo, e como argumenta Baev (2004, pp. 274-5), em 2003, o presidente Putin percebeu que "a administração Bush não tinha, nem a intenção de retirar da Ásia Central, nem a capacidade para reforçar a sua presença militar ao ponto de se tornar a potência regional dominante", o que criava oportunidades para a atuação da Rússia.

A eleição do presidente Medvedev, em 2008, representou uma opção política pela continuidade das políticas desenvolvidas pelo presidente 
Putin (Freire e Simão, 2008). Isto coincidiu com um realismo crescente da Rússia no contexto internacional e com o seu desejo de reconstruir as fundações do Estado russo, em desenvolvimento nos últimos anos (Kanet, 2008, p. 8; Freire, 2009, p. 129). Medvedev apresentou uma agenda liberal de modernização, onde as relações com o ocidente eram fundamentais e que muitos no ocidente esperavam pudesse definir uma nova era nas relações com os EUA e a Europa, num potencial regresso ao espírito dos anos 1990 (Averre, 2010). Na Rússia, contudo, o sentimento predominante foi de algum ceticismo e cautela. Ilustrando isto, a Estratégia de Segurança Nacional da Federação Russa até 2020 (ESN), apresentada em maio de 2009, identifica uma ligação clara entre a capacidade de a Rússia defender a sua segurança nacional e o potencial económico do país (de Haas, 2009, p. 3; ESN, 2009). Esta ligação subentende, por isso, uma parceria de modernização com os parceiros norte-americanos e europeus, que poderá ser posta em causa face às políticas expansionistas da OTAN na Eurásia, nomeadamente a política de alargamento e a PfP, e face aos frutos limitados da política de 'reset' com os EUA. Ou seja, na medida em que a ESN liga a segurança nacional com o desenvolvimento socioeconómico da Rússia e que ambos estão profundamente dependentes da qualidade das relações de Moscovo com o ocidente, a direção que estas duas dinâmicas tomar será fundamental para a postura russa noutros cenários internacionais, como a Ásia Central, onde a cooperação com os EUA e a UE é fundamental.

O enfoque de Medvedev nas parcerias para a modernização da Rússia ditou um certo afastamento face à região, que pouco tem para oferecer nesta vertente. Por outro lado, a falta de uma resposta eficaz de Moscovo, ao pedido de ajuda do Quirguistão, para lidar com os conflitos interétnicos que abalaram o sul do país em 2010, ilustrou a falta de preparação da Rússia para exercer liderança regional. Mostrou também a ineficácia da OTSC para dar resposta a conflitos intraestatais nos seus membros. Apesar da carta fundadora da organização ter sido revista para contemplar essa possibilidade, a desconfiança que caracteriza as relações entre os seus membros deverá criar obstáculos políticos à ação atempada em casos semelhantes. 


\section{Política externa russa na Ásia Central: que futuro?}

De facto, as dinâmicas em curso aquando da chegada do presidente Medvedev ao Kremlin foram continuadas. A Rússia manteve uma política de crescente envolvimento económico e militar na Ásia Central, distribuindo ajuda financeira e investindo em sectores altamente lucrativos das economias regionais (Barry, 2009). Contudo, apesar dos esforços para reforçar uma "esfera de interesses privilegiados", a Rússia deparou-se com o facto de "não ser [hoje] mais fácil lidar com os vizinhos da Ásia Central, do que tem sido ao longo das últimas duas décadas" (Kanet, 2010, p. 93). Para além das dificuldades nas relações bilaterais e no âmbito das organizações regionais da Ásia Central, as opções políticas de Moscovo nesta região têm sido influenciadas por dinâmicas das suas próprias relações com as potências europeias e os EUA. Por exemplo, após a breve guerra na Geórgia, em 2008, e o esfriar de relações com o ocidente, Moscovo procurou apoio no âmbito da CEI e da OCX para o reconhecimento das regiões separatistas na Abcázia e da Ossétia do Sul, sem resultados.

Para as políticas externas multivetoriais dos Estados da Ásia Central, a competição por influência entre várias potências hegemónicas serve o objetivo de proteger as elites regionais de pressão unilateral. Esta competição tem favorecido o status quo, embora apresentando respostas muito limitadas para os desafios regionais. As perspetivas de que isto venha a mudar são limitadas, apesar da crescente pressão social, económica, financeira e de segurança sobre os regimes da região. Para a Rússia, salvaguardar a sua posição regional hegemónica, especialmente contra a presença militar dos EUA tem sido uma prioridade. Tal como afirma Deyermond (2009, p. 171), mesmo que exista uma coexistência pacífica na Ásia Central, a Rússia fez da preservação do seu papel hegemónico, na área de segurança na Ásia Central, uma parte fundamental da sua política. À medida que os EUA se preparam para retirar do Afeganistão, a competição estratégica tenderá a diminuir, diminuindo também o risco de conflito hegemónico entre Washington e Moscovo. Contudo, isto também colocará pressão acrescida sobre a Rússia para que responda aos desafios securitários da região e assuma o papel de garante da 
segurança regional. A capacidade política e operacional limitada da Rússia em atuar como garante da segurança regional ficou bem visível no caso dos conflitos no Quirguistão em 2010, e no Tajiquistão, em agosto de 2012, quando, após o assassinato do responsável pelo gabinete do Comité Estatal para a Segurança Nacional na província de Gorno Badakhshan, o governo de Emomalii Rahmon enviou tropas que mantiveram a região isolada, sob a justificação de lutar contra forças extremistas e desleais ao governo (The Economist, 2012; ver também a entrevista com o analista Andrei Grozin, 2012).

Em termos da competição hegemónica comercial, financeira e de soft power, esta deverá manter-se alimentada pela presença de potências aspirantes como a China e a Índia. Esta competição teve já os seus impactos na região, em pelo menos duas ocasiões. A primeira foi a capacidade da China quebrar o monopólio russo sobre a exportação de recursos energéticos da região. A inauguração do oleoduto ligando o Turquemenistão à China, a 14 de dezembro de 2009, garante, pela primeira vez, acesso chinês aos recursos do Cáspio e permite a compra direta de recursos aos Estados da região, sem mediação russa. Um outro exemplo da crescente tensão entre a Rússia e a China foi visível na crise política no Quirguistão, em 2010. A abertura ao investimento chinês nos projetos hidroelétricos do país foi um elemento adicional de tensão entre Bisqueque e Moscovo, que tinha sido o principal financiador do regime e em particular destes projetos (Simão, 2010). Em parte, este foi um factor importante na queda do regime do presidente Bakiev, em abril de 2010, facilitado pela retirada do apoio de Moscovo e pela campanha difamatória que os meios de comunicação russos veicularam contra o regime.

Tal como argumentado por Menon (2007), o alinhamento de interesses russos e chineses na Ásia Central, alimentado primordialmente pelo desejo de contrabalançar a presença norte-americana, corre um risco real de vir a desaparecer com a gradual retirada norte-americana do Afeganistão e à medida que o equilíbrio regional de poder se altera a favor da China.

"A questão central é a de saber se a convergência dará lugar à rivalidade ou se a Rússia, perante a constatação dos limites do seu poder, 
irá gradualmente acomodar a hegemonia chinesa na região, criando um processo de mudança histórica, onde Moscovo passa da aceitação da competição na sua esfera de influência, por parte de um conjunto de Estados (o que faz atualmente, mesmo que por necessidade), para a cedência da supremacia a um Estado.” (Menon, 2007, p. 12)

\section{Conclusão}

O principal argumento deste capítulo é que a crescente complexidade da competição hegemónica em curso na Ásia Central representa um risco real de instabilidade e conflito na região. Este contexto está diretamente ligado às políticas de Moscovo e às suas relações com outras potências regionais. O modelo da hegemonia multinível permite-nos conjugar os elementos de interdependência regional e global que se cruzam no espaço da Ásia Central, resultantes dos processos de globalização desta região. Efetivamente, as opções de Moscovo parecem ter seguido um padrão reativo numa primeira fase, caracterizada pela necessidade de reorganização interna e simultaneamente impelido pelas ligações provenientes do seu passado imperial nesta região contígua ao seu território. Numa segunda fase, já sob a liderança do presidente Putin, a Rússia abraçou a competição regional, mostrando alguma ambivalência entre a presença norte-americana na região, no pós-11 de setembro - da ótica de Moscovo, um mal necessário -, e a consolidação de uma esfera de interesses privilegiados numa região cada vez mais disputada. Finalmente, podemos dizer que a Rússia se encontra numa fase de consolidação da sua presença militar, económica e política na região, embora num plano de longo prazo esta consolidação deva continuar a ser desafiada, quer pelos atores regionais, quer pelas outras potências hegemónicas a atuar na região.

O contexto atual é de grande urgência em garantir que a Ásia Central não caia num ciclo vicioso de instabilidade política, criminalidade e violência que colocaria uma pressão insuportável sobre os frágeis regimes da região e as suas sociedades. As lições da história mostram-nos que a resposta das elites no poder é o reforço dos padrões autoritários, o que 
enfraqueceria ainda mais estes Estados. À medida que os EUA se preparam para retirar da região, a tendência será de maior liberdade de movimento das forças a operar na região, posicionando-se como novas ameaças. Apesar de a Rússia reclamar para si o papel de garante de segurança na região, tem sido relutante em colocar forças no terreno quando solicitada, quer no quadro dos acordos bilaterais, quer no quadro da OTSC.

Neste contexto, o papel do Uzbequistão tornar-se-á crucial para a (in) estabilidade regional, podendo contribuir para novas fontes de tensão regional. Neste momento, esta possibilidade é particularmente preocupante para o Quirguistão, devido ao contexto político vulnerável do país e a incapacidade de gerir as relações com a considerável minoria uzbeque, no sul do país, no Vale de Fergana. A saída uzbeque da OTSC representa também um desafio adicional de coordenação da ação militar e política, sob liderança russa, num cenário pós-retirada norte-americana. Com o regresso de Vladimir Putin ao Kremlin, em 2012, o sentido da política externa russa para a Ásia Central não deverá ser alterado. Se pensarmos que o mandato de Medvedev representou apenas uma quebra formal, mas não substancial, do exercício do poder por Putin, então este novo mandato permitirá continuar os processos em curso. Segundo Trenin (2012), a diversificação e modernização económica manter-se-á uma prioridade, exigindo relações estáveis com os EUA e a Europa, o que por sua vez deverá ditar uma maior cooperação no âmbito da retirada das forças norte-americanas do Afeganistão e na estabilização da Ásia Central.

Esta atenção aos aspetos económicos está também plasmada nos projetos anunciados de criar uma União Euroasiática, que deverá desenvolver-se tendo por base a União Aduaneira já existente entre a Rússia, a Bielorrússia e o Cazaquistão, com vista à criação de um mercado único, onde poderão participar os Estados interessados. Esta opção de integração económica poderá ser bastante atrativa para os governos e sociedades da Ásia Central, criando melhores acessos ao mercado russo para os produtos e, especialmente, para os trabalhadores da região. O principal problema para países como o Quirguistão, prende-se com o aumento das barreiras alfandegárias para aqueles que permanecerão fora deste mercado único, nomeadamente a China que domina o mercado quirguiz. Esta é, aliás, uma 
das prioridades de Moscovo com este projeto, mas que irá criar tensões e dificuldades para as políticas comerciais dos Estados da região. Para além disso, as divisões entre as cinco repúblicas ex-soviéticas são profundas, o que mina a visão de um espaço geográfico contíguo integrado a nível económico. Independentemente das dificuldades, os projetos económicos e a cooperação militar manter-se-ão aspetos centrais da presença russa na região e das dinâmicas de competição com outras potências regionais.

\section{Bibliografia}

AKINER, Shirin - Tajikistan: Disintegration or Reconciliation? London: The Royal Institute of International Affairs, 2001.

ALLISON, Roy - Conclusion: Central Asian Security in the Regional and International Context. In Roy Allison e Lena Jonson (eds.), Central Asian Security: The New International Context. London: Royal Institute of International Affairs (2001), p. 247-268.

ANTONENKO, Oksana - Putin's Gamble. Survival. Vol. 43, N. ${ }^{\circ} 4$ (2001), p. 49-60.

ASMUS, Ronald D. - A Little War that Shook the World: Georgia, Russia, and the Future of the West. New York: Palgrave Macmillan, 2010.

AVERRE, Derek - Triangulation or Strangulation? The US, the EU and Russia in European Security Governance. Artigo apresentado na 'UACES Annual Conference', Bruges, 6-8 setembro 2010.

BAEV, Pavel K. - Assessing Russia's Cards: Three Petty Games in Central Asia. Cambridge Review of International Affairs. Vol. 17, N. ${ }^{\circ} 2$ (2004), p. 269-283.

BARRY, Ellen - Russia's Neighbors Resist Wooing and Bullying”, The New York Times, 2 julho 2009. [Acedido a 20 de set. de 2010]. Disponível na Internet: http://www.nytimes. com/2009/07/03/world/europe/03russia.html.

BURGHART, Dan - The New Nomads? American Military Presence in Central Asia. China and Eurasia Forum Quarterly. Vol. 5, N. ${ }^{\circ} 2$ (2007), p. 5-19.

BUZAN, Barry e WAEVER, Ole - Regions and Powers: The Structure of International Security. Cambridge: Cambridge University Press, 2003.

Casa Branca - U.S.-Russia Relations: 'Reset' Fact Sheet. The White House, Office of the Press Secretary, 24 junho 2010. [Acedido a 14 de fev. de 2012]. Disponível na Internet: http:// www.whitehouse.gov/the-press-office/us-russia-relations-reset-fact-sheet.

Conceito de Política Externa da Federação Russa (1993) Reproduzido in Melville, Andrei e Shakleina, Tatiana, eds. (2005). Russian Foreign Policy in Transition: Concepts and Realities. Budapest: CEU Press, p. 27-64.

CORNELL, Svante E. - The Narcotics Threat in Greater Central Asia: From Crime-Terror Nexus to State Infiltration? China and Eurasia Forum Quarterly. Vol. 4, N. 1 (2006), p. 37-67.

CUTLER, Robert - U.S.-Russian Strategic Relations and the Structuration of Central Asia. Perspectives on Global Development and Technology. Vol. 6, N. ${ }^{\circ} 1-3$ (2007), p. 109-125.

DE HAAS, Marcel - Medvedev's Security Policy: A Provisional Assessment. Russian Analytical Digest. N. ${ }^{\circ} 62$ (2009), p. 2-5. 
DEYERMOND, Ruth - Matrioshka Hegemony? Multi-leveled Hegemonic Competition and Security in Post-Soviet Central Asia. Review of International Studies. Vol. 35, N. 1 (2009), p. 151-173.

DIGOL, Diana - Russia's foreign policy in Central Asia: From Yeltsin to Medvedev. In Maria R. Freire e Kanet, Roger E., eds., Russia and its Near Neigbbours. Basingstoke: Palgrave Macmillan (2012), p. 174-202.

Economist, The - Troubled Tajikistan: Where Cure Begets Disease. The Economist Asia View, 23 setembro 2010. [Acedido a 14 de set. de 2010]. Disponível na Internet: http://www.economist. com/blogs/asiaview/2010/09/troubled_tajikistan. Consultado em: 14 setembro 2010.

Economist, The - Violence in Tadikistan. The strongman cometh. The Economist, 28 julho 2012. [Acedido a 30 de ago. de 2012]. Disponível na Internet: http://www.economist. com/node/21559664.

ESN - Estratégia de Segurança Nacional da Federação Russa até 2020, 12 maio 2009. [Acedido a 31 de ago. de 2010]. Disponível na Internet: http://www.scrf.gov.ru/documents/99.html.

EurasiaNet - Russia to Establish Air Base in Kyrgyzstan, Deals Blow to US Strategic Interests in Central Asia, 2 dezembro 2002. [Acedido a 14 de set. de 2010]. Disponível na Internet: http://www.eurasianet.org/departments/insight/articles/eav120302.shtml.

EurasiaNet - Uzbekistan and Russia Sign Mutual Defense Pact, 14 novembro 2005. [Acedido a 14 de set. de 2010]. Disponível na Internet: http://www.eurasianet.org/departments/ insight/articles/eav111505.shtml.

FENOPETOV, Vladimir - The Drug Crime Threat to Countries Located on the 'Silk Road'. China and Eurasia Forum Quarterly. Vol. 4, N. ${ }^{\circ} 1$ (2006), p. 5-13.

FREIRE, Maria R. - Russian Policy in Central Asia: Supporting, Balancing, Coercing, or Imposing? Asian Perspective. Vol. 33, N. 2 (2009), p. 125-149.

FREIRE, Maria R. - Tempo de balanço: as presidências de Barack Obama e Dmitri Medvedev. Relações Internacionais. N. ${ }^{\circ} 34$ (2012), p. 61-72.

FREIRE, Maria R. e Licínia Simão - As eleições presidenciais na Rússia: continuidade na mudança. IPRI Occasional Paper, no. 32, março 208 - 2008. [Acedido a 26 de set. de 2010]. Disponível na Internet:http://www.ipri.pt/publicacoes/working_paper/working paper.php?idp=231.

FRIEDMAN, Uri - Russian press rips Romney and his promise of 'Republican hell'. Foreign Policy, 30 agosto 2012. [Acedido a 9 de set. de 2012]. Disponível na Internet: http:// blog.foreignpolicy.com/posts/2012/08/30/russian_press_rips_romney_and_his_promise_ of_republican_hell.

GARNETT, Sherman W., RAHR, Alexander e WATANABE, Koji - The New Central Asia: In Search of Stability. New York, Paris e Tokyo: The Trilateral Commission, 2000.

GROZIN, Andrei - Andrei Grozin: as operações na região de Badakhshan no Tajiquistão estavam preparadas desde a primavera, Entrevista ao jornal eletrónico Regnum (em russo), 2012. [Acedido a 9 de set. de 2012]. Disponível na Internet:http://www.regnum. $\mathrm{ru} /$ news/polit/1555574.html.

GULLETTE, David - Kyrgyzstan: Components of Crisis. OpenDemocracy, 28 junho 2010. [Acedido a 3 de set. de 2010]. Disponível na Internet:http://www.opendemocracy.net/ david-gullette/kyrgyzstan-components-of-crisis.

HILL, Fiona - Une stratégie incertaine: la politique des États-Unis dans le Caucase et en Asie centrale depuis 1991. Politique Étrangère. Vol. 66,N. ${ }^{\circ} 1$ (2001), p. 95-108.

HILL, Fiona - The United States and Russia in Central Asia: Uzbekistan, Tajikistan, Afghanistan, Pakistan, and Iran. Brookings, 15 agosto 2002. [Acedido a 27 de set. de 2010]. Disponível na Internet:http://www.brookings.edu/speeches/2002/0815russia_hill.aspx. 
HILL, Fiona - Central Asia and the Caucasus: The Impact of the War on Terrorism. In Adrian Karatnycky, Alexander J. Motyl e Amanda Schnetzer, eds., Nations in Transit 2003. Lanham, MD: Rowman e Littlefield (2003), p. 39-50.

Internation Crisis Group - Central Asia: Water and Conflict. International Crisis Group, Asia Report, N. ${ }^{\circ}$ 34, 30 maio (2002a).

Internation Crisis Group - Central Asia: Border Disputes and Conflict Potential. International Crisis Group, Asia Report, N. ${ }^{\circ} 33,4$ abril (2002b).

Internation Crisis Group - The Curse of Cotton: Central Asia's Destructive Monoculture. International Crisis Group, Asia Report, N. ${ }^{\circ}$ 93, 28 fevereiro 2005.

INDYK, Martin; LIEBERTHAL, Kenneth e O'HANLON, Michael - Scoring Obama's Foreign Policy. A Progressive Pragmatist Tries to Bend History", Foreign Policy, maio/junho 2012. [Acedido a 9 de set. de 2012]. Disponível na Internet: http://www.foreignaffairs. com/articles/137516/martin-indyk-kenneth-lieberthal-and-michael-e-ohanlon/scoringobamas-foreign-policy.

JACKSON, Nicole J. - Russian Foreign Policy and the CIS: Theories, Debates and Actions. New York: Routledge, 2003.

JANUSZ, Barbara - The Caspian Sea: Legal Status and Regime Problems. Russia and Eurasia Programme, Chatham House, REP bp 05/02, agosto 2005.

JENTLESON, Bruce W. e KUPCHAN, Charles A. - A Dangerous Mind. Foreign Policy, 30 agosto 2012. [Acedido a 9 de set. de 2012]. Disponível na Internet: http://www. foreignpolicy.com/articles/2012/08/30/a_dangerous_mind_mitt_romney.

JONSON, Lena - Russia and Central Asia. In Roy Allison e Jonson, Lena, eds., Central Asian Security: The New International Context. London: Royal Institute of International Affairs (2001), p. 95-126.

KANET, Roger E. - The return of Imperial Russia: Russia and its Neighbors. ACDIS Occasional Paper, setembro 2008. [Acedido a 13 de maio de 2010]. Disponível na Internet: http:// acdis.illinois.edu/assets/docs/309/TheReturnofImperialRussiaRussiaandItsNeighbors.pdf.

KANET, Roger E. - Russia and the Greater Caspian Basin: Withstanding the US Challenge. In Maria R. Freire e Kanet, Roger E. eds., Key Players and Regional Dynamics in Eurasia: The Return of the 'Great Game'. Basingstoke: Palgrave Macmillan (2010), p. 81-102.

KOBRINSKAYA, Irina - The CIS in Russian Foreign Policy: Causes and Effects. In Hanna Smith, ed., Russia and Its Foreign Policy. Saarijärvi: Kikimora Publications (2005), p. 77-92.

KRAMER, Andrew E. - New Gas Pipeline from Central Asia Feeds China. The New York Times, 14 dezembro 2009. [Acedido a 9 de jun. de 2011]. Disponível na Internet: http:// www.nytimes.com/2009/12/15/world/asia/15pipeline.html.

LARUELLE, Marléne - Asie Centrale: Le retour de la Russie. Politique Internationale, . $^{\circ}$ 115, primavera 2007. Versão eletrónica. [Acedido a 12 de set. de 2010]. Disponível na Internet: http://www. politiqueinternationale.com/revue/read2.php?id_revue=115\&id=630\&content=texte.

LARUELLE, Marlène, PEYROUSE, Sébastien, HUCHET, Jean-François e BALCI, Bayram, eds. China and India in Central Asia: A New 'Great Game'? New York: Palgrave Macmillan, 2010.

LUBIN, Nancy - Who's Watching the Watchdogs?: Drug Trafficking in Central Asia. In Dan Burghart e Sabonis-Helf, Theresa, eds., In the Tracks of Tamerlane: Central Asia's Path to the 21st Century. Washington, D.C.: National Defense University, Center For Technology and National Security Policy (2004), p. 361-376.

MARAT, Erica - The Changing Dynamics of State-Crime Relations in Kyrgyzstan. Central Asia Caucasus Institute Analyst, 20 fevereiro 2008. [Acedido a 20 de set. de 2010]. Disponível na Internet:http://www.cacianalyst.org/?q=node/4796. 
MARAT, Erica - Bakiyev, the Security Structures, and the April 7 Violence in Kyrgyzstan. Central Asia Caucasus Institute Analyst, 28 abril 2010. [Acedido a 20 de set. de 2010]. Disponível na Internet: http://www.cacianalyst.org/?q=node/5316.

MARKEDONOV, Sergei - Post-Soviet Integration: Does the CIS Work?. OpenDemocracy, oD Russia Post-Soviet World, 13 janeiro 2010. [Acedido a 31 de ago. de 2010]. Disponível na Internet: http://www.opendemocracy.net/od-russia/sergei-markedonov/post-sovietintegration-does-cis-work.

MENON, Raja - Introduction: Central Asia in the Twenty-First Century. In Eugene Rumer, Trenin; Dmitri e Zhao, Huasheng, eds. Central Asia: Views from Washington, Moscow, and Beijing. New York: M.E. Sharpe (2007), p. 3-17.

POMFRET, Richard - Central Asia and the Global Economic Crisis. EU Central Asia Monitoring (EUCAM), 7 junho 2009. [Acedido a 31 de ago. de 2010]. Disponível na Internet: http:// www.eucentralasia.eu/fileadmin/user_upload/PDF/Policy_Briefs/PB-7-eversion.pdf.

PRATT, Martin e SCHOFIELD, Clive - International Boundaries, Resources and Environmental Security in the Caspian Sea. In Blake, Gerald; Chia Lin Sien; Grundy-Warr, Carl; Pratt, Martin e Schofield, Clive, eds., International Boundaries and Environmental Security: Frameworks for Regional Cooperation. London: Kluwer Law International (1997), p. 81-104.

RASHID, Ahmed - The Resurgence of Central Asia: Islam or Nationalism? London: Zed Books, 1994.

RASHID, Ahmed - Jihad: Ascensão do Islão Militante na Ásia Central. Tradução de Freitas e Silva, Lisboa: Terramar, 2002.

RFE/RL - Tajikistan: First Permanent Russian Military Base Opened", Radio Free Europe/ Radio Liberty, 17 outubro 2004. [Acedido a 31 de ago. de 2010]. Disponível na Internet: http://www.rferl.org/content/article/1055375.html.

SAKWA, Richard e Webber, Mark - The Commonwealth of Independent States, 1991-1998: Stagnation and Survival. Europe-Asia Studies. Vol. 51, N. 3 (1999), p. 379-415.

SIMÃO, Licínia - Carta de Bisqueque: Da democracia na Ásia Central. Relações Internacionais. N. ${ }^{\circ} 26$ (2010), p. 61-66.

STEPANOVA, Ekaterina - Does Russia Want the West to Succeed in Afghanistan?. PONARS Eurasia Policy Memo, N. ${ }^{\circ}$ 61, setembro 2009.

SWANSTROM, Niklas; Cornell, Svante e Tabishalieva, Anara - A Strategic Conflict Analysis of Central Asia with a Focus on Kyrgyzstan and Tajikitan. Central Asia-Caucasus Institute \& Silk Road Studies Program, junho 2005. [Acedido a 28 de set. de 2010]. Disponível na Internet:www.silkroadstudies.org/docs/publications/2005/SIDA_CA.pdf.

TRENIN, Dmitri - Russia and Central Asia: Interests, Policies, and Prospects. In Rumer, Eugene; Trenin, Dmitri e Huasheng Zhao, Central Asia: Views from Washington, Moscow, and Beijing. New York: M.E. Sharpe (2007b), p. 75-136.

TRENIN, Dmitri - What Will Putin Do in Foreign Policy? Carnegie Endowment for International Peace, maio 2012.

WILHELMSEN, Julie e FLIKKE, Geir - Evidence of Russia's Bush Doctrine in the CIS. European Security. Vol. 14, N. ${ }^{\circ} 3$ (2005), p. 387-417.

XING, Guangchend - China and Central Asia. In Allison, Roy e Jonson, Lena, eds., Central Asian Security: The New International Context. London: Royal Institute of International Affairs (2001), p. 152-170. 
